\title{
Exercise capacity in chronic heart failure is related to the aetiology of heart disease
}

\author{
Andrew L Clark, Derek Harrington, Tuan Peng Chua, Andrew J S Coats
}

\begin{abstract}
Objective-To assess whether the underlying aetiology of chronic heart failure is a predictor of exercise performance.

Setting-Tertiary referral centre for cardiology.

Patients and outcome measuresRetrospective study of maximum exercise testing with metabolic gas exchange measurements in 212 patients with chronic heart failure who had undergone coronary angiography. Echocardiography and radionucleide ventriculography were used to determine indices of left ventricular function, and coronary arteriography was used to determine whether the cause of chronic heart failure was ischaemic heart disease $(n=122)$ or dilated cardiomyopathy $(\mathrm{n}=90)$.

Results-The cardiomyopathy group was younger (mean (SD) age 58.45 (11.66) years $v 61.49(7.42) ; p=0.02)$ but there was no difference between the groups in ejection fraction or fractional shortening. Peak oxygen consumption $\left(\dot{V}_{2}\right)$ was higher in the dilated group, while the slope relating carbon dioxide production and ventilation ( $\dot{\mathrm{V}} / \dot{\mathrm{V}}_{\mathrm{CO}_{2}}$ slope) was the same in both groups. Both groups achieved similar respiratory exchange ratios at peak exercise, suggesting that there was near maximum exertion. There was a relation between peak $\dot{V}_{o_{2}}$ and age (peak $\dot{\mathrm{V}} \mathrm{o}_{2}=33.9-0.267^{\star}$ age; $\left.r=0.36 ; \mathrm{p}<0.001\right)$. After correcting for age, the peak achieved $\dot{\mathbf{V}} \mathrm{O}_{2}$ was still greater in the cardiomyopathy group than in the ischaemic group $(\mathrm{p}<0.002)$.
\end{abstract}

Conclusions-Exercise performance for a given level of cardiac dysfunction appears to vary with the aetiology of heart failure. Thus the two diagnostic categories should be considered separately in relation to abnormalities of exercise physiology. The difference may in part account for the worse prognosis in ischaemic patients. (Heart 1997;78:569-571)

Keywords: exercise performance; heart failure; ischaemic heart disease; dilated cardiomyopathy

Chronic heart failure is a clinical syndrome resulting from heart muscle damage of varying aetiologies. Most commonly in western societies, chronic heart failure is secondary to ischaemic heart disease, but many patients have dilated cardiomyopathies of unknown origin with normal coronary arteries. ${ }^{1}$ Less commonly in the developed world, chronic heart failure is due to valvar heart disease. In investigating the pathophysiology of exercise impairment in chronic heart failure, many investigators have grouped patients together regardless of the aetiology of the failure. ${ }^{23}$

Many previous reports on the aetiology of chronic heart failure have used non-invasive tests. ${ }^{4}$ Pilot studies from our group (unpublished) have suggested that a significant proportion of cases could be misclassified between ischaemic and non-ischaemic cardiomyopathies unless coronary angiography was performed. This misclassification may reach $10 \%$ and would lessen any differences in prognosis between these two main diagnostic categories.

We sought to investigate whether patients with a similar level of cardiac dysfunction had similar exercise performance regardless of aetiology when accurately assessed by coronary angiography. This information could determine whether it is appropriate to group patients together in investigating exercise performance in chronic heart failure.

\section{Methods}

We analysed data from 212 consecutive patients from the Royal Brompton heart failure database. All patients referred to the heart failure clinic undergo symptom limited exercise testing with metabolic gas exchange testing when their clinical condition is stable. Only those patients who had undergone coronary arteriography are included in this study. Patients were diagnosed as having dilated cardiomyopathy in the presence of left ventricular dysfunction where the coronary arteries were either anatomically normal or had no coronary artery stenosis greater than $50 \%$.

Exercise testing was undertaken using a modified Bruce protocol, with the patient connected by a one way valve to a respiratory mass spectrometer. Expired gas was analysed to derive oxygen consumption $\left(\dot{\mathrm{V}}_{2}\right)$, carbon dioxide production $\left(\dot{\mathrm{V}} \mathrm{CO}_{2}\right)$, and ventilation ( $\dot{V} E)$. Patients were encouraged to exercise to exhaustion. Continuous 12 lead electrocardiographic monitoring was used. Patients were excluded if the test was positive or the patient had anginal chest pain on exercise.

Standard echocardiographic measurements of left ventricular function derived from the long axis parasternal window were available in 143 patients. In 166 patients, left ventricular ejection fraction had been estimated using radionucleide ventriculography. 
Table 1 Comparison of dilated cardiomyopathy and ischaemic heart disease patient groups

\begin{tabular}{lllc}
\hline & $D C M(n=90)$ & IHD $(n=122)$ & p value \\
\hline Age (years) & $58.45(11.66)$ & $61.49(7.42)$ & 0.02 \\
LVEF (\%) & $28.2(17.1)$ & $25.7(12.1)$ & 0.27 \\
Fractional shortening (\%) & $19.2(10.2)$ & $16.5(9.8)$ & 0.1 \\
Peak $\dot{V}_{2}(\mathrm{ml} / \mathrm{kg} / \mathrm{min})$ & $19.9(7.9)$ & $16.4(5.4)$ & $<0.001$ \\
$\%$ Predicted $\dot{\mathrm{V}} \mathrm{O}_{2}$ & $68.8(27.2)$ & $53.6(17.2)$ & $<0.001$ \\
$\dot{\mathrm{V}} / \mathrm{V} \mathrm{CO}_{2}$ slope & $34.7(10.9)$ & $37.1(12.8)$ & 0.15 \\
RER at peak & $1.19(0.15)$ & $1.15(0.18)$ & 0.1 \\
\hline
\end{tabular}

$\mathrm{LVEF}$, left ventricular ejection fraction; $\dot{\mathrm{V}} \mathrm{O}_{2}$, oxygen consumption; $\dot{\mathrm{VE}} / \dot{\mathrm{V}}_{\mathrm{CO}_{2}}$ slope, slope of the relation between ventilation and carbon dioxide production; RER, respiratory exchange ratio.

Predicted peak $\dot{\mathrm{V}}_{2}$ was calculated from the formulae of Wasserman et $a \bar{l}$ which predicts peak $\dot{\mathrm{V}}_{2}$ on the basis of gender, age, and weight. Raw data were also corrected for age by analysis of covariance using age as a covariate.

\section{Results}

The crude data are shown in table 1 . The patients with dilated cardiomyopathy were younger but appeared to have the same level of cardiac impairment as estimated by left ventricular ejection fraction and fractional shortening. There was no difference between the two diagnostic groups in ejection fraction or fractional shortening. The raw data suggest that peak $\dot{\mathrm{V}}_{2}$ was higher in the dilated cardiomyopathy group, while the slope relating $\mathrm{V}_{\mathrm{CO}_{2}}$ and $\dot{\mathrm{V}}_{\mathrm{E}}$ was the same in both groups. Both groups achieved similar respiratory exchange ratios at peak exercise, suggesting that there was at least near maximum exertion in both groups. ${ }^{6}$ There was no difference between the two groups in the symptoms at peak exercise (shortness of breath in $69.6 \%$ of the ischaemic group and $64.4 \%$ of the dilated cardiomyopathy group).

Overall there was a significant relation between peak $\dot{\mathrm{V}}_{2}$ and age (peak $\dot{\mathrm{V}}_{2}=33.9-0.267^{\star}$ age; $\left.r=0.36 ; \mathrm{p}<0.001\right)$. The peak $\dot{\mathrm{V}}_{2}$ expressed as a percentage of the predicted peak $\dot{\mathrm{V}}_{2}$ was significantly greater for the dilated cardiomyopathy group. After correcting for age, the peak achieved $\dot{\mathrm{V}}_{2}$ was still greater in the cardiomyopathy group than in the ischaemic group $(p<0.002)$. There was a weak relation between $\dot{\mathrm{V}} \mathrm{E} / \dot{\mathrm{V}}_{\mathrm{CO}}$ and age $(\dot{\mathrm{V}} \mathrm{E} /$ $\dot{\mathrm{V}} \mathrm{CO}_{2}=20.5+0.26^{\star}$ age; $\left.r=0.20 ; \mathrm{p}=0.004\right)$, but there was no difference between the two diagnostic categories. There was a very weak relation between peak $\dot{\mathrm{V}}_{2}$ and both left ventricular ejection fraction $(r=0.22$; $\mathrm{p}<0.001)$ and fractional shortening $(r=0.27$; $\mathrm{p}<0.001)$. There was no interaction between measures of left ventricular function and diagnostic category.

\section{Discussion}

Previous studies designed to investigate exercise physiology in chronic heart failure have included patients with heart failure regardless of aetiology. ${ }^{23}$ This approach has potential problems. Patients whose heart failure is secondary to ischaemic heart disease may have widespread vascular disease, and their exercise performance may be limited by peripheral vascular factors. Even in the absence of angina or electrocardiographic changes, such patients may be stopped by myocardial ischaemia manifesting itself as breathlessness. ${ }^{7}$ Conversely, patients with a dilated cardiomyopathy may have a skeletal muscle myopathy as part of their illness. This is most obviously seen in genetically determined myopathies. ${ }^{8}$ Exercise performance in these patients may be limited by factors other than heart failure. A further complicating feature is that the chronic heart failure syndrome itself is associated with skeletal muscle abnormalities, ${ }^{9}{ }^{10}$ which appear to be related to exercise capacity ${ }^{11}$ and may be related to progression of the syndrome.

Most prognostic studies have reported that patients with ischaemic cardiomyopathy have a worse outlook than those with a non-ischaemic aetiology, ${ }^{12}{ }^{13}$ although occasional studies suggest that the reverse may be true. ${ }^{14}$ We have found that for a given level of cardiac dysfunction, patients with heart failure due to nonischaemic heart disease have a higher peak $\dot{\mathrm{V}}_{2}$ than patients with coronary artery disease. This did not appear to be associated with any difference in the ventilatory response to exercise as measured by the $\dot{\mathrm{V}} / \dot{\mathrm{V}}_{\mathrm{CO}}$ slope. The implication must be that in studying exercise physiology in chronic heart failure the two different groups should be treated separately.

Trial data suggest that there may be differential effects of treatment on outcome in the two aetiological groups. ${ }^{15-17}$ There are no published data on the subject, but it would seem likely that a proportion of patients with chronic heart failure have their aetiologies misclassified. The data from the present study suggest that this misclassification would dilute any effect of aetiology on prognosis. Coronary arteriography should be considered in patients with heart failure to make a definite diagnosis of the aetiology, so allowing better risk stratification and perhaps in the future allowing for different therapeutic requirements.

\section{LIMITATIONS}

This is a retrospective review of data acquired from patients referred to a tertiary referral service for patients with heart failure. There may be referral bias so that only the more limited patients with ischaemic heart disease are referred to our practice. Further, we excluded from analysis an additional 64 patients in the database: 32 patients who had not undergone angiography as they had a past history of myocardial infarction and 22 in whom the principal symptom on exercise was chest pain or who had an electrocardiographically positive exercise test. Fourteen patients had a presumptive diagnosis of dilated cardiomyopathy on the basis of echocardiographic appearances and history but had not undergone coronary arteriography.

We have no data from this survey to enable us to say whether differences in exercise capacity are reflected in differences in outcome. It is possible that the ischaemic patients were stopping exercise due to "anginal equivalent" or ischaemic left ventricular dysfunction, however, and patients with conventionally "positive" tests were excluded. Forty four patients had resting left bundle branch block. These 
subjects may have had undetected ischaemia during exercise. Both the dilated cardiomyopathy and ischaemic heart disease groups achieved similar respiratory exchange ratios at peak exercise.

1 Manolio TA, Baughman KL, Rodeheffer R, Pearson TA, Bristow JD, Michels W, et al. Prevalence and etiology of idiopathic dilated cardiomyopathy. $\mathrm{Am} \mathcal{F}$ Cardiol 1992;69:1458-66.

2 Metra M, Dei Cas L, Panina G, Visiolo O. Exercise hyperventilation in chronic congestive heart failure, and its relation to functional capacity and hemodynamics. $A m \mathcal{F}$ Cardiol 1992;70:622-8.

Cardiol 1992;70:622-8.
3 Puri S, Baker LB, Dutka DP, Oakley CM, Hughes JMB, Cleland JGF. Reduced alveolar-capillary membrane diffusing capacity in chronic heart failure. Circulation 1995;91: 2769-74.

4 Hillis GS, Al-Mohammad A, Wood M, Jennings KP Changing patterns of investigation and treatment of cardiac failure in hospital. Heart 1996;427:427-9.

5 Wasserman K, Hansen JE, Sue DY, Whipp BJ. Principles of exercise testing and interpretation. Philadelphia: Lea and Febiger, 1986:73.

6 Clark AL, Poole-Wilson PA, Coats AJS. Effects of motivation of the patient on indices of exercise capacity in chronic heart failure. Br Heart $\mathcal{F}$ 1994;71:162-5.

7 Cook DG, Shaper AG. Breathlessness, angina pectoris and coronary artery disease. Am F Cardiol 1989;63:921-4.

8 Perlov JK. Neurological disorders and heart disease. In: Braunwald E, ed. Heart disease, 3rd ed. Philadelphia: WB Saunders, 1988:1782-99.
9 Lipkin DP, Jones DA, Round JM, Poole-Wilson PA. Abnormalities of skeletal muscle in patients with chronic heart failure. Int $\mathcal{F}$ Cardiol 1988;18:187-95.

10 Mancini DM, Walter G, Reichek N, Lenkinski R, McCully KK, Mullen JI, et al. Contribution of skeletal muscle atrophy to exercise intolerance and altered muscle metabolism in heart failure. Circulation 1992;85:1364-73.

11 Volterrani M, Clark AL, Ludman PF, Swan JW, Adamopoulos S, Piepoli M, et al. Determinants of exercise capacity in chronic heart failure. Eur Heart f 1994;15:801-9.

12 Franciosa JA, Wilen M, Ziesche S, Cohn JN. Survival in men with severe chronic left ventricular failure due to either coronary heart disease or idiopathic dilated cardiomyopathy. Am 7 Cardiol 1982;51:831-6.

13 Kelly TK, Cremo R, Nielsen C, Shabetai R. Prediction of outcome in late-stage cardiomyopathy. Am Heart $\mathcal{F}$ 1990;119:1111-21.

14 Gradman A, Deedwania P, Cody R, Massie B, Packer M, Pitt B, et al. Predictors of total mortality and sudden death in mild to moderate heart failure. $\mathcal{F}$ Am Coll Cardiol 1989; 14:564-70.

15 CIBIS investigators and committees. A randomised trial of beta-blockade in heart failure: the Cardiac Insufficiency Bisoprolol Study (CIBIS). Circulation 1994;90:1665-73.

16 Singh SN, Fletcher RD, Fisher SG, Singh BN, Lewis HD, Deedwania PC, et al. Amiodarone in patients with congestive heart failure and asymptomatic ventricular arrhythmia. N Engl f Med 1995;333:77-82.

17 Packer M, O'Connor CM, Ghali JK, Pressler ML, Carson PE, Belkin RN, et al. Effect of amlodipine on morbidity and mortality in severe chronic heart failure. $N \mathrm{Engl} \mathcal{7} \mathrm{Med}$ 1996;335:1107-14. 